\title{
A LITERATURA INFANTIL: (MENOR)IDADE E DESTERRITORIALIZAÇÕES
}

Aline Rodrigues dos SANTOS ${ }^{1}$

Roselene de Fátima COITO ${ }^{2}$

Universidade Estadual de Maringá - UEM

Resumo: pensando o lugar da literatura infantil e da criança na sociedade como um lugar de uma possibilidade de dizer, do dizer e de se dizer, a investigação aqui proposta se pauta nas miragens infantis, femininas e feministas que se projetam a partir de uma personagem da literatura infanto-juvenil. Assim sendo, nosso objetivo é discutir como se entende a literatura infantil e juvenil como literatura menor, a partir da filosofia de Deleuze e Guattari, tendo como corpus o texto Procurando Firme, 1984, de Ruth Rocha, procedendo com análises discursivas, pela perspectiva foucaultiana, das miragens femininas, feministas e infantis, que se constituem linguisticamente na narrativa. Pudemos perceber a literatura da criança, mesmo marginalizada pelo cânone, pela academia e pelo discurso literário tradicional, constituindo sua menoridade como máquina de revolução, máquina de expressão coletiva e desterritorialização $d a$ servidão infantil à palavra do adulto $e$ da servidão do gênero feminino à palavra do gênero "majoritário", desvelando que a própria condição de menor, faz dessa literatura arte transgressiva que se abre ao devir.

Palavras-chave: literatura infantojuvenil, discurso, devir, feminismo.

\begin{abstract}
: thinking the place of children's literature and of the child in society as a place of a possibility to say, to the saying and to say itself, the research proposed here is based on the childish, feminine and feminist mirages that are project from a character of the children literature. Thus, our aim is to discuss how understand children literature as a minor literature, based on the Deleuze and Guattari's philosophy, having as corpus the text "Procurando Firme", 1984, by Ruth Rocha, proceeding with discursive analyzes, by the Foucaultian perspective, of mirages feminine, feminist, and childish, which constitute linguistically in the narrative. We could perceive the children literature, even marginalized by the canon, the academy and the traditional literary discourse, constituting its minority as a machine of revolution, a machine of collective expression and deterritorialization of child servitude to the word of the adult and the servitude of the feminine gender to the word of the "majoritarian" gender, showing that the condition of a minor literute, makes it transgressive art that opens to becoming.
\end{abstract}

Keywords: children literature, discourse, becoming, feminism.

\footnotetext{
${ }^{1}$ Mestra na área de Estudos Linguísticos, linha de pesquisa: Estudos do Texto e do Discurso, pela Universidade Estadual de Maringá - UEM. Integra o grupo de pesquisa GPLEIADI. Graduada em Letras Português/Inglês pela UNESPAR, campus de Campo Mourão.

2 Possui graduação em Letras pela Universidade Estadual Paulista Júlio de Mesquita Filho (1990), mestrado em Estudos Literários pela Universidade Estadual Paulista Júlio de Mesquita Filho (1996) e doutorado em Estudos Literários pela Universidade Estadual Paulista Júlio de Mesquita Filho (2003). Realização do Pósdoutorado nos anos de 2008-2009 na Ecole des Hautes Etudes en Sciences Sociales - Paris
} 


\section{Introdução}

A maneira como a literatura infantil irrompeu e se desenvolveu no Ocidente, absorvida pelas instituições pedagógicas, apoiada em saberes moralizantes e em mecanismos de coerção e vigilância, ora interditada, ora incitada à produção em nome da administração da vida dos mais jovens retirou-a do "reduto seleto da literatura" (ZILBERMAN E CADEMARTORI, 1984, p. 04). Nessa perspectiva, denominá-la como literatura menor significa que "para muitos não é considerada literatura e por isso não entra no cânon literário e nem se estabelece, de fato, uma crítica específica" (COITO, 2003, p.109).

Coito (2006) afirma que essa cultura é herança dos gregos (primeiro em Sócrates, depois Platão) que acreditavam que a literatura infantil deveria ser "gerenciada" pela família e pelo Estado, especialmente por ser discurso direcionado aos jovens, indivíduos muito suscetíveis diante do perigo do poder de sedução do discurso artístico. Rebaixar o status e esvaziar tal literatura do caráter artístico se deve, nesse sentido, a seu poder de transgressão e efeitos de sedução, considerando, primordialmente, o público ao qual ela se dirige. Diante desse jogo da periculosidade e da interdição, Santos (2018) traça algumas considerações sobre esse estatuto de menoridade:

Pensemos esse lugar de menoridade, coagido, interditado e não artístico da literatura infantil (...) ter se mantido até os dias de hoje a partir das considerações de Michel Foucault: "por mais que o discurso seja aparentemente bem pouca coisa, as interdições que o atingem revelam logo, rapidamente, sua ligação com o desejo e com o poder" (FOUCAULT, 2014, p. 09 e 10) $)^{3}$. Essa aparência de menoridade do discurso literário infantil revela (...) o poder desse discurso e como tal foi e é desejado pela vontade de verdade das sociedades através dos tempos devido a sua importância na ordem dos saberes e poderes da sociedade de controle, pois, sobrevive na linha tênue do perigo e da dominação, portanto, do futuro da vida da sociedade e da manutenção (ou não) de sua ordem de acordo com o público ao qual é destinado (SANTOS, 2018, p. 36).

Tendo em vista esse lugar de sobrevivência entre a dominação e o perigo de transgredi-la, desvelado pelo desejável poder de tal discurso, que constantemente coloca em cheque a verdade que o interdita é que compreendemos a literatura infantil como

\footnotetext{
${ }^{3}$ FOUCAULT, M. A ordem do discurso. Trad. Laura Fraga de Almeida Sampaio. 24. ed. São Paulo: Loyola, 2014.
} 
menor, ou seja, fora da perspectiva do cânone, da pedagogia, da academia e também do mercadológico.

Assim, a perspectiva de literatura menor que consideramos é aquela apresentada por Gilles Deleuze e Félix Guattari na obra Kafka Por uma literatura Menor (1975). Partindo da célebre frase dos autores, "uma literatura menor não é a de uma língua menor, mas antes a que uma minoria faz em uma língua maior" (DELEUZE E GUATTARI, 2015, p. 35), é que dizemos que tal literatura é aquela que escapa à reprodução dos códigos já estabelecidos, da dependência dos discursos oficiais; as instâncias de legitimação não lhe são vitais e nem sua existência depende das instituições que selecionam e excluem o que é ou não arte de tradição.

Seu ponto central é a desterritorialização que o menor faz dentro do maior, por isso, é máquina literária que se constitui máquina revolucionária. Implica uma metamorfose, um movimento de deslocamento que um povo ou um grupo marginalizado faz na busca por novos caminhos. No caso de Kafka, fica claro como essa marginalização da língua se faz em função do choque de culturas que vai do espacial ao político: "como devir o nômade e o imigrante e o cigano da sua própria língua? Kafka diz: roubar a criança no berço, dançar sobre a corda bamba" (DELEUZE E GUATTARI, 2015, p. 41). A literatura infantil é, pois, o nômade, o imigrante e o cigano em sua própria língua, é a literatura do jovem, do inculto, da linguagem "simples e banal" em face da literatura do adulto. Perante seu desejável poder, tal marginalização desvela, ao contrário, seu caráter transgressivo, de expandir limites de coerção e vigilância, de reunir em si o coletivo, o político - a as outras duas características da literatura menor - pela capacidade de "ser em sua própria língua como um estrangeiro" (Ibidem, p. 47, grifo dos autores).

Observamos aqui o eixo que guia o pensamento de Deleuze e Guattari dialogando com os pensamentos de Foucault sobre o discurso literário como aquele que "rompe com toda definição de 'gêneros' como formas ajustadas a uma ordem de representações..." (FOUCAULT, 2000a, p. 59). Reiteremos, a língua menor é aquela da variação e da destruição, por isso, quando se trata de literatura infantil, extrapola-se o pedagógico, o selo do banal, do lazer e do entretenimento já que as possibilidades do menor nunca são o mesmo, mas o devir.

Sendo assim, nos propomos a discutir a literatura infantil e juvenil como literatura menor, a partir da filosofia de Deleuze e Gattari, tendo como corpus o texto Procurando 
Firme, 1984, de Ruth Rocha, com o objetivo de analisar miragens femininas, feministas e infantis, que se constituem linguisticamente na narrativa

Uma questão essencial para noção de desterritorialização é a noção do devir. Abrir a possibilidade do novo pela "raridade dos talentos" ", ausência do cânone ou da tradição implica no deslocamento das próprias estruturas linguísticas que operam como máquina coletiva de expressão, já que essa língua não tem outro compromisso senão com a consciência de uma minoria. Nesse sentido, o devir da linguagem é próprio devir da vida pela arte.

A arte literária menor é a máquina revolucionária da luta das minorias buscando espaços de liberdade e se constitui, como nenhum outro discurso, como aquele que curva relações de força de modo a descaracterizar condutas, modelos culturais, identidades etc. Diante disso, trazemos o conceito de miragens, situando-nos dentro da perspectiva discursa foucaultiana e pensando esse conceito à luz de algumas de suas noções teóricas e nos pontos onde elas se encontram com a filosofia de Deleuze e Guattari e com a perspectiva feminista do gênero produzido nas e pelas práticas discursivas, principalmente nas noções de estilos ou artes de vida, discurso, transgressão e devir. Não tratamos, portanto, de identidades, mas daquilo que sempre suscita o devir. As miragens, diferentemente das identidades, não possuem compromisso com o "real", pois não se tratam do 'real' representado tal e qual. Elas nunca são fixas, estão sempre em função dos efeitos de um discurso transgressivo que move o sujeito diante das transformáveis linhas de interpretação (SANTOS, 2018, p. 64). Ou seja, não exatamente o devir, mas estão sempre caminhando em sua direção,

O discurso literário não impõe interpretações, mas questiona o leitor, porque constantemente o deixa passível de novos sentidos, de forma que esse pode se reconhecer nas personagens literárias, não reconhecerse ou interpretar-se parcialmente nelas (...) a literatura não precisa e nem procura a fidelidade do leitor porque não é sua função demarcarlhes espaços e modelos; por isso uma miragem nunca coincide totalmente com a realidade, mas pode sugerir-lhes alguns traços, além do que, o olhar jogado sobre a miragem projetada pode não ser o mesmo que já foi e nem o mesmo a todos os olhos que a miram, pois é isso que é a interpretação: móvel, fluída e transformável (...) (SANTOS, 2018, p. 65).

\footnotetext{
${ }^{4}$ Deleuze e Guattari (2015) refletem que os talentos não abundam na literatura menor. Não há um mestre inaugurador de uma estética ou gênero que (re) defina um fazer literário e sirva de modelo aos demais.
} 
Procurando Firme conta a história de uma princesa e um príncipe, ambos são irmãos e crescem no mesmo castelo sob treinamentos específicos para se tornarem princesa e príncipe ideais. $\mathrm{O}$ irmão recebe aulas de atividades que o preparam para correr mundo, ou seja, viver no espaço público, e assim o faz logo no início da narrativa. A história se desenrola, então, com foco na menina que fica no castelo treinando atividades domésticas à espera de um outro príncipe que irá enfrentar o dragão e propor-lhe casamento, até o dia em que ela muda seu destino.

\section{A primeira característica é a desterritorialização}

"Mas a primeira característica, de toda maneira, é que, nela, a língua é afetada de uma forma coeficiente de desterritorialização" (DELEUZE E GUATTARI, 2015, p. 35), declaram os filósofos. Nesse sentido, a linguagem menor é aquela que desvia e desrespeita a estética do maior, criando usos intensivos da língua. $\mathrm{O}$ alemão de Praga com seu "vocabulário ressecado", "sintaxe incorreta" e influenciado pelo Tcheco inaugura um novo/outro entendimento da obra de Kafka. Recorrendo às discussões de Wagenbach ${ }^{5}$, os filósofos assinalam que "todos esses traços de pobreza de uma língua se reencontram em Kafka, mas tomados em uso criador... a serviço de uma nova sobriedade, de uma nova expressividade, de uma nova flexibilidade, de uma nova intensidade" (Ibidem, p. 46 e 47).

A desterritorialização que tratam aqui é o movimento da língua com seus verbos, conjunções, advérbios, pronomes etc., marcado pelos abusos e erros que ultrapassam os limites e instauram usos extremos da língua. Só a literatura menor tem a linguagem do intensivo extremo do limite, já que trabalha como língua estranha, nômade. O exercício menor de uso de uma língua é a condição da máquina revolucionária ou, ainda, a condição de constituir uma máquina coletiva de expressão. Quando faz vibrar o novo - "abrir a palavra sobre intensidades interiores inauditas" (Ibidem, p. 45), faz irromper as vidas inauditas das minorias. Cai a metáfora e o simbolismo; os sons e as palavras desterritorializadas trabalham a própria matéria no fluxo de uma linha de fuga. Não há metáfora, há metamorfose. "Trata-se de um devir" (Ibidem, p. 45).

\footnotetext{
${ }^{5}$ WAGENBACH. Praga na virada do século. P. 78 a 88. 
Em Procurando Firme, muitos são os usos menores da língua. O texto é marcado pela informalidade de uma história de princesa contada entre os diálogos de duas crianças:

- Puxa vida! Não há quem aguente mais essas histórias! Dá um tempo!

- Espera um pouco, ô! Você não sabe ainda como a história é.

- Ah, isso eu sei! Aposto que tem castelo!

- Ah, tem, castelo tem.

- E tem rei e rainha.

- Ah, rei e rainha também tem.

(...)

- Puxa vida! E você vem dizer que não é uma daquelas histórias chatíssimas, que a princesa fica a vida inteira esperando o príncipe encantado?

- Ah, vá, deixa eu contar. Depois você vê se gosta. Que coisa! (ROCHA, 2009, p, 06)

Nesses enunciados, o abuso das interjeições fica evidente, essas palavras invariáveis que expressam sem a necessidade de usos elaborados de estruturas linguísticas. O estado de espírito das personagens ao dizerem Ah!, Puxa vida! e Que coisa! se resume mesmo nessas pequenas estruturas que poderiam se desenrolar em longas frases um tanto mais explicativas :Ah, vá, deixa eu contar por por favor, não me interrompa, deixa eu contar. Mas, nesse caso, ecoaria o novo? A história de princesa abalaria o lugar comum dos contos de fadas e inauguraria a história que parece de fadas, mas não é, assim como o livro, logo de início, é apresentado? A repetição dessas categorias abre para a voz minoritária infantil. Essa repetição de elementos linguísticos simples favorece a linguagem menor da criança que fala no lugar da tradicional voz que narra o conto de fadas e desenvolve uma outra literatura (uma outra história que tem príncipe, princesa, castelo, rei e rainha, mas não é de fadas e tampouco daquelas histórias chatíssimas). Nesta mesma/outra história, vejamos como a princesa é apresentada nos enunciados:

Enquanto isso a princesinha, irmã do príncipe, que era linda como os amores e tinha os olhos mais azuis que o azul do céu, e tinha os cabelos mais dourados do que as espigas do campo e que tinha a pele branca como as nuvens nos dias de inverno...

(...)

A pele da princesa era branca, pronto. $\mathrm{E}$ as mãos da princesa eram macias como... Ah, não importa. As mãos eram macias, os pés eram pequenos, e a voz da princesa era maviosa.

- Maviosa?

- É, maviosa, melodiosa! Eu sei que essa palavra não se usa mais, mas se eu não usar umas palavras bonitas, meio difíceis, vão ficar 
dizendo que eu não incentivo à cultura dos leitores (ROCHA, 2009, p. 11 e 12).

Além da insistência das repetições (e tinha, e tinha, e que tinha) e interjeições, que já apontamos aqui, outro aspecto nos chama a atenção: a sequência de adjetivação. A personagem vai recebendo caracterização - linda, loura, pele branca, mãos macias, pés pequenos e voz maviosa - até se produzir a imagem da tradicional e convencional princesa bela e frágil. No entanto, a maneira como a voz infantil narradora se estrutura faz com que salte das palavras o tom da conversa entre as crianças, como se não houvesse apenas uma voz que narra, mas essas duas vozes que se responsabilizam pela tessitura da personagem (no caso, da personagem dentro do conto) e do fazer narrativo. A criança que conta a história ora está a mercê da que ouve, ora escapa, ora controla, assim como a que ouve, ora ouve, ora conta a história: - Maviosa? Ou: - Ah, isso eu sei! Aposto que tem castelo!

Fica evidente que esta narrativa não está "na situação de uma língua rica ordinária" (DELEUZE E GUATTARI, 2015, p. 44), especialmente pelo tom satírico pelo qual o termo "maviosa" foi usado. Esse termo passa da caracterização da voz da princesa e se torna o referente do dizer. Consciente do fluxo de menoridade que se instala em sua linguagem, Ruth Rocha satiriza a literatura maior que insiste em aliar cultura a um vocabulário formal que, muitas vezes, é composto por palavras que já caíram em desuso e, mais, satiriza a ideia da existência da soberania de uma cultura sobre a outra que se concretiza nos conceitos de belo e difícil - palavras bonitas e difíceis para quem? Para as crianças? Para os incultos? - O termo qualificador maviosa passa por uma metamorfose, não é mais a simples qualificação da voz da princesa e nem o recurso para "enriquecer" o vocabulário e atender a uma exigência do tradicionalismo, não é mais nem a metáfora ou a simbologia do que seria uma palavra bonita e difícil, é palavra desterritorializada que faz abalar a metáfora, a tradição e a própria categoria de adjetivo.

Mas a literatura menor não é apenas aquela que ultrapassa a metáfora e instala o máximo de diferença da literatura maior pelos sons e palavras, ela é a revolução experimentada por uma minoria, é a própria condição revolucionária de fugir e fazer fugir um povo das condições da realidade presente: “é o mesmo que dizer que 'menor' não qualifica mais certas literaturas, mas as condições revolucionárias de toda literatura no seio daquela que se chama grande (ou estabelecida)" (DELEUZE E GUATTARI, 2015, p. 38). Abrir o máximo de diferença é forjar, na singularidade da língua menor, a 
subversão dos sentidos majoritários. Eleger a voz infantil para narrar a história da princesa abre para a possibilidade de operar com a simplicidade vocabular e sintática e, assim como em Kafka, a música, usada como matéria de expressão, suscita o devir porque é atravessada pela insensatez e pela desorganização, o nome da princesa é usado nesta narrativa também como matéria de expressão que abre para o devir atravessado ao mesmo tempo pelo nome e pelo não nome. Dito de outra forma, é uma desterritorialização de um referente singular - o nome nomeia e especifica alguém - para um referente indefinido e plural.

Então a mãe da Linda Flor (a princesa se chamava Linda Flor, eu já contei?) (ROCHA, 2009. p. 28).

(...)

E não queria mais ser chamada de Linda Flor.

- Que nome mais careta! Quero que me chamem de Teca, de Zaba, de Mari, um nome mais moderninho! (ROCHA, 2009. p. 28).

No conto de fadas convencional, o nome próprio da princesa assume um lugar de importância, muitas vezes sendo o próprio nome dela, o nome do conto. Aqui, o nome instaura os dois diferentes momentos em que a personagem se encontra. No primeiro momento, ela é Linda Flor, a princesa bela e frágil, como assim se espera, marcada por uma feminilidade delicada daquilo que ela é e daquilo que ela faz: é linda como os amores e estática como uma flor que espera o príncipe que enfrentará o dragão e pedirá sua mão em casamento. $\mathrm{O}$ nome Linda Flor assume importância no conto, porém pelas vias da desorganização - diríamos, a importância pela via da não importância, pois é citado apenas na metade da narrativa já que a personagem narradora "esquece" de mencioná-lo antes.

A mudança do estado de quem espera (pelo casamento) acontece também pelo fluxo do nome. A menina não é mais quem apenas é (é linda/Linda), mas passa a ser quem se torna. A transformação de sua experiência para quem pratica a si mesma se dá no abandono do velho nome para fazer falar o novo, no entanto, este novo existe, pois é dito (... não queria mais ser chamada de... quero que me chamem de...), mas é inaudível, pois fica indefinido, a história termina sem que ela escolha um novo nome para si. Não é mais nem Linda Flor, nem Teca, nem Zaba e nem Mari, é devir. Do nome, fica apenas a subtração do velho e a possibilidade do novo, ou seja, a metamorfose. Em Kafka a música não organiza o que é homem, o que é animal e o que é a metáfora de ambos; na linguagem 
infantil da personagem, o nome não define quem ela se torna, o nome está lá (mais moderninho) pelo não nome.

A literatura menor que se constitui nesses enunciados, pelo trabalho com a linguagem infantil é a matéria de expressão que forja muito além do que uma personagem feita de nome e não nome, mas de tudo o que é histórico e social e que se assenta nesses dizeres sobre o que é ser e não ser uma menina princesa, dito de outro modo, ser feminina. O empreendimento dessa linguagem é pela metamorfose - máquina revolucionária, pela criação de novas possibilidades de vida ao subtrair o que a personagem é para projetar miragens ao devir, a princesa não é mais a princesa ideal, da mesma forma que sua feminilidade não o é, a princesa também não se torna definitivamente outra coisa, ela está sempre por se tornar, "a coisa e as outras coisas não passam de intensidades percorridas pelos sons ou pelas palavras desterritorializadas seguindo sua linha de fuga" (DELEUZE E GUATTARI, 2015, p. 45).

\section{"Tudo nela é político"}

"A segunda característica da literatura menor é que tudo nela é político" (Idem,

2015, p. 36); a existência linguística é a própria existência política de uma minoria. A linguagem menor não é aquela que parte de uma experiência individual que pode, posteriormente, ser interpretada e usada pelo coletivo; ela já parte do coletivo, pois trabalha politicamente para resistir e contestar o uso majoritário da língua. A literatura menor já emerge como máquina revolucionária no seio de uma coletividade marginalizada. Assim, a narrativa sobre a princesa já irrompe literatura menor ao enunciar nessa linguagem "esvaziada" do que é bonito e difícil por se tratar da linguagem infantil. Analisemos agora, esse menor infantil aliado ao menor feminino como objeto de um dizer.

No enunciado agora, a princesa da nossa história estava deixando o tempo passar que é pra esperar um príncipe encantado que vinha derrotar o dragão e casar com ela (ROCHA, 2009, p. 16), o gênero, o casamento, o trabalho e a esfera privada são alguns dos campos associados que emergem na superfície discursiva e são passíveis de perceber como aqueles que se atravessam para formar a conduta esperada de uma princesa. No entanto, tanto essa conduta quanto esses campos associados são produções históricas e sociais, a partir de determinadas tecnologias, segundo verdades que se 
sustentam em conhecimentos fabricados e oferecidos ao feminino. Teresa de Lauretis, teórica feminista, propõe que pensemos o gênero na esteira de Foucault e sua teorização acerca da sexualidade:

(,,,) começar a pensar o gênero a partir de uma visão teórica foucaultiana, que vê a sexualidade como uma "tecnologia sexual"; desta forma, propor-se-ia que também o gênero, como representação e como auto-representação, é produto de diferentes tecnologias sociais, como o cinema, por exemplo, e de discursos, epistemologias e práticas críticas institucionalizadas, como das práticas da vida cotidiana (LAURETIS, 1994, p.208)

A conduta da feminilidade da princesa nada mais é do que uma produção e produto social ancorada em procedimentos institucionalizados, também, pelas relações de trabalho - relações saber-poder como as duas dimensões que formam o sujeito em Foucault, principalmente em seus textos Verdade e Subjetividade (1993) e O sujeito e o Poder (1995). Os verbos e a locução verbal em destaque são o estado estático da princesa, representada como aquela que, de fato, não faz nada além de deixar o tempo passar e esperar o príncipe que iria lhe propor casamento. Esse estado estático de espera é associado às atividades domésticas que ela fazia enquanto deixava o tempo passar:

A princesa se ocupava de ocupações principescas, quer dizer, a princesa tomava aulas de canto, de bordados, de tricô, de pintura em cerâmica. A princesa fazia cursinhos de iniciação à poesia de Castro Alves, estudava um pouquinho de piano, fazia flores de marzipã (...) (ROCHA, 2009, p. 13).

A naturalidade em que as atividades dela são apresentadas se ancora na ordem econômica que dissipou o trabalho entre gêneros como aquilo que seria inútil e aquilo que seria produtivo. Os espaços públicos e privados igualmente se dissiparam e se organizaram nas representações de oposição entre o que é pessoal, afetivo, familiar e economicamente improdutivo e o que é economicamente ativo, produtivo e gerador de riquezas. Dessa forma, o trabalho doméstico é sempre recolocado como o lugar do inútil, do nada, da simples espera pelo casamento: Pois é, naquele reino era muito bonito ter prendas... - É, saber fazer coisas que não servem pra nada, que é pra todos saberem que a pessoa é rica... (Ibidem, p. 13 e 14). Assim, em primeira análise, pode-se dizer que os verbos que expressam o estado de inércia se ligam diretamente ao canto, ao bordado, ao tricô, à pintura, às ocupações principescas, enfim. 
No entanto, esse determinismo natural de separação entre o público e o privado e, portanto, o produtivo e o inútil, desvela o funcionamento de certas verdades produzindo o gênero por meio dessas atividades (ocupações principescas). Tudo o que a personagem faz é dentro do campo de ação permitido ao seu status social de princesa, assim, como todas essas atividades se desenvolvem com o único fim de esperar o casamento. Linda Flor (que neste momento ainda possui nome) não é em si mesma apenas ela, mas todo o feminino sobre o qual pesou a administração e manutenção da vida familiar sob a aparência do nada e do inútil. D'Incao, ao estudar a vida da mulher burguesa desde os primeiros momentos da formação da classe, discute sobre sua preparação para o casamento que tem de ser feita durante toda sua vida e disso depende também a manutenção do matrimônio enquanto instituição, assim como do cuidado da mãe depende todo o prolongamento dos componentes da vida familiar e a vida do marido como homem público. O trabalho doméstico é, acima de tudo, a garantia da perpetuação da vida econômica da família, pois sobre ele está a manutenção ou não da classe (D’INCAO, 2012, p. 225 a 228).

O feminino, neste caso, é coletivo e sua constituição entrelaça suas ações, gestos aparência e conduta nas relações de trabalho que, sob a aparência do determinismo natural que separa o inútil do produtivo, desvela-se político e se sustenta na prática do casamento. As tecnologias que moldam o gênero feminino (o canto, o bordado, o tricô, a pintura etc.) e constroem uma conduta adequada ao casamento demonstram que o pessoal e o privado não são inúteis, mas políticos já que se constituem em instituições sobre as quais se perpetua uma ordem econômica. Na narrativa, observamos que quando o primeiro príncipe sobe a torre e propõe casamento à Linda Flor, o esforço da mãe é para que ela garanta o casamento, usando para isso as habilidades que ela passara a vida desenvolvendo: - Filhinha, filhinha, vai fazer uma baba-de-moça pro moço, vai... e ainda - Que é isso, minha filha, você nunca, nunquinha na sua vida teve preguiça... Então vai fazer uns fiozinhos d'ovos pro moço ver como você é prendada... (ROCHA, 2009, p. 20 e 21).

Na literatura menor, a história individual é encharcada pelo coletivo e, por isso, é imediatamente política. Em Linda Flor reúne-se não somente a mulher burguesa responsável pela tutela da família, mas todas as mulheres cujo feminino se formou por meio das tecnologias que as punham sempre no doméstico e modulam seu labor como inútil. Deleuze e Guattari dizem que "seu espaço exíguo (da literatura menor) faz que 
cada caso individual seja imediatamente ligado à política. O caso individual torna-se, então, tanto mais necessário, indispensável, aumentado ao microscópico, quanto toda uma outra história se agite nela" (2015, p. 36). É a história dessas mulheres que "se agita" na história da princesa entre as miragens da inutilidade e do necessário labor feminino, já que essa inércia se trata somente da aparência que reveste as técnicas políticas e econômicas que produzem a personagem. Não há, pois, a identidade da princesa, mas um despedaçamento de efeitos de sentido que projetam as mais plurais miragens sobre o gênero, o trabalho, o privado, o público, o político, enfim.

\section{E toma um valor coletivo}

A literatura maior constrói seus cânones a partir de um longo trajeto que consiste em olhar para o passado e buscar referências na tradição para que se possa classificar uma obra que, se entra para este reduto seleto, passa do individual ao coletivo. No Brasil, mesmo que dentro da própria literatura infanto-juvenil haja a institucionalização na escolha das obras que podem ou não compor o quadro do que é arte literária (em separação do que é entretenimento), os próprios escritores da literatura infantil e juvenil se constituem pela ausência e desvalorização em face da literatura maior - a do adulto ${ }^{6}$.

Essa inadequação ao maior se estende à atualidade e, por isso, é que dizemos ser a literatura infanto-juvenil estrangeira em seu próprio país. Nela não há escritora ou escritor que se trate quase que como uma instituição dentro de outra instituição. Não há a fundadora ou fundador de uma estética sobre a qual as outras obras devam se debruçar. De maneira geral, as obras literárias infantis e juvenis já são concebidas com valor coletivo diante dessa "raridade de talentos". Eis a terceira características de literatura menor:

A terceira característica é que tudo toma um valor coletivo. Com efeito, precisamente porque os talentos não abundam numa literatura menor, as condições de uma enunciação individual não são dadas, que seria de um tal ou qual "mestre", e poderia ser separada da enunciação coletiva. De maneira que esse estado de raridade dos talentos é de fato benéfico, e permite conceber outra

\footnotetext{
6 Basta ver o exemplo daquele que é considerado pela crítica o precursor e divisor de águas da produção da literatura para os mais jovens, no Brasil, e o que teremos é o status de grande autor para a literatura “menor" infanto-juvenil, mas um Pré-Modernista para a crítica majoritária, mesmo tendo Monteiro Lobato produzido intensamente durante o período Modernista. Talvez isso se deva mesmo ao fato de que sua produção não se dedicou ao adulto com a mesma intensidade com a qual se entregou ao menor.
} 
coisa que uma literatura de mestres: o que o escritor sozinho diz já constitui uma ação comum, e o que ele diz ou faz é necessariamente político, mesmo que os outros não estejam de acordo. O campo político contaminou todo o enunciado (DELEUZE E GUATTARI, 2015, p. 44).

A obra Procurando Firme assume as suas próprias menoridades - a menoridade do infantil e a menoridade do feminino - e é esse o privilégio do menor: desviar-se do maior. Ela diz o infantil e o feminino desrespeitando o modelo tradicional da língua maior e o modelo tradicional imposto à mulher. Aliás, escarnecer do maior é regularidade nessa obra. Além do uso deslocado de palavras como maviosa, frivolité e marzipã (é um doce muito caro, que ninguém come mais, que não há dinheiro que chegue... (p. 14)), escarnece do determinismo natural que impunha à mulher maneiras de ser submissa, fragilizada $\mathrm{e}$ dependente do gênero "maior". Retomemos alguns enunciados e logo perceberemos o atravessamento do discurso pedagógico ao narrar a princesa que tomava aulas para se tornar a princesa ideal, de gestos delicados e que sabe muito bem desenvolver atividades domésticas. Sobre isso, recorremos ainda a outro enunciado que descortina a tese da determinação natural do gênero frágil, inerte e inútil e, de maneira escarnecedora, traz à luz o processo de constituição do feminino por técnicas de modulação do gênero: $E a$ rainha desmaiou ali mesmo, mas ninguém se incomodou muito porque a rainha adorava desmaiar. Aliás, ela vivia dizendo que a princesa precisava tomar umas aulas de desmaio, que era muito útil desmaiar nas horas certas.

É perceptível que as três características da literatura menor se entrelaçam. A língua menor é máquina revolucionária que subverte verdades e modelos majoritários e isso só é possível porque sua escrita já nasce imersa na coletividade, o sujeito do enunciado é construção coletiva. A voz que narra a história da princesa é a voz coletiva infantil simplificada, quebrada, cheia de cortes monossílabos. A conduta da princesa, mostrada em seu processo de fabricação por meio de aulas das mais variadas atividades domésticas, não é aquela diretamente ordenada do conto de fadas tradicional, em que a menina é naturalmente bela e boa e, por isso, recebe o casamento com o príncipe como recompensa; trata-se, antes, da conduta coletiva do gênero menor desnudado da aparência da improdutividade econômica e da pouca participação política.

Nas primeiras análises do nome da princesa, discutimos sua passagem do estado de quem espera para o estado de quem não se define mais nem pelo casamento nem pela espera do príncipe, mas está sempre por se tornar outra coisa. Pelo fluxo do nome e do 
não nome, a menina amplia seus modos de existência e passa por constituir-se numa miragem que se reduplica ao devir. No trecho abaixo, dois sujeitos majoritários são confrontados, a menoridade do infantil e do feminino confronta as conversas dos mais velhos e as conversas dos ministros:

(...) que deu para rir alto e até se intrometia nas conversas dos mais velhos. Até nas conversas dos ministros sobre política ela deu para dar palpites! E não queria mais ser chamada de Linda Flor.

- Que nome mais careta! Quero que me chamem de Teca, de Zaba, de Mari, um nome mais moderninho! (ROCHA, 2009. p. 28).

A desterritorialização é coletiva, o menor infantil se funde ao menor feminino de modo que a personagem se constitui agora na constante recriação de si mesma e nas práticas de liberdade. Mais uma vez, já não há mais Linda Flor, nem Teca, nem Zaba, nem Mari, nem princesa ideal, mas miragens do infantil e do feminino que se fazem e desfazem a cada interpretação, "trata-se de um devir que compreende, ao contrário, o máximo de diferença como diferença de intensidade, atravessamento de um limiar, elevação ou queda, baixa ou ereção, acento de palavra” (DELEUZE E GUATTARI, 2015, p. 45).

\section{Considerações finais}

Neste complexo dizer sobre e dizer-se, a literatura enquanto um discurso que circula nas mais diferentes esferas da sociedade, seja ela considerada arte ou não, sempre é, de alguma forma, institucionalizada diante de seu desejável poder, e neste desejo de ser e no desejo de dizer ser, isto é, enquanto um discurso, não escapa a coerções e vigilâncias, ainda mais quando se propõe a ocupar estas desterritorializações do que se diz, como se diz e sobre quem se diz. No entanto - no Brasil, mesmo depois de sua crescente produção e de seu movimento transgressivo intenso, a partir da década de 60, da inauguração de estudos específicos dirigidos a ela na universidade, na década de 80 , e sua expansão mercadológica nos últimos anos, ainda encontra-se ausente e subestimada diante da literatura do adulto, considerada a que efetivamente representa a cultura oficial do país. No entanto, não é nosso objetivo trabalhar para que ela passe a compor esse discurso oficial e a ocupar lugar de igualdade no cânone e na academia, mas refletir como que, em sua menoridade, ela tem poder artístico e, mesmo à margem, constitui o conjunto cultural 
de sua contemporaneidade ao desvelar a multiplicidade e as contradições que sobrevivem dentro de uma cultura.

Acima de tudo, a literatura infantil e juvenil, ausente dos grandes patamares da cultura e da arte oficiais por sua linguagem infantil e "simples" é a própria possibilidade de desterritorializar os menores da servidão: "Quantas pessoas vivem hoje uma língua que não é a sua?... e conhecem mal a língua maior de que são forçadas a servir?” (DEUEZE E GUATTARI, 2015, p. 40). Empreender estudos sobre esse discurso poderoso, capaz de transgredir o estado de servidão da língua da criança, e da própria criança, é, paralelamente, problematizar a dominação da língua do adulto, a dominação daquilo que se entende como criança e, também, da, talvez pretensa, dominação do que se entende como feminino, levando-se em consideração, sempre o entendimento do fluxo da escritura como miragens possíveis de possíveis devires.

Como fluxo de escritura transgressiva, a literatura menor infantil e juvenil é capaz de escapar da banalidade dos temas e tratar com a criança de problemáticas que profundamente se enraízam numa cultura e perpetuam a ordem pelas relações de poder, como é o caso da menoridade atribuída ao feminino. Procurando firme faz falar, pelo e para o infantil, o lugar subjugado da mulher ao mesmo tempo em que fala da própria resistência feminina a esses processos que a inferiorizam, colocando a questão não como pano de fundo da narrativa, como pretexto para que a personagem represente uma heroína, mas como discurso constituinte da tessitura da personagem, um dizer que a produz e é a própria condição da(s) desterritorialização(ões), da máquina coletiva de expressão e da máquina revolucionária.

Por isso, intentamos aqui, nesta breve reflexão, perceber a irrupção das miragens infantis e femininas/feministas dentro do discurso artístico literário da (menor)idade como um lugar de desterritorializações, que da máquina coletiva de expressão pode sempre vir a ser uma máquina revolucionária do dizer, do se dizer e de dizer-se.

\section{Referências}

COITO, R. F. A inquietude do discurso literário infantil de Clarice Lispector - Sob a ótica da Análise do Discurso. Alemanha, Verlag: Edições Acadêmicas, 2016.

. A Literatura Infantil na(s) sociedade(s): Os discursos da periculosidade da arte. Revista Trama, V. 2, n. 4, $2^{\circ}$ semestre 2006, p. 205-217. 
DELEUZE, G.; GATTARI, F. Kafka por uma literatura menor. Trad. Cíntia Vieira da Silva. Belo horizonte: Autêntica Editora. 1ed. 2015.

D'INCAO, M. A. Mulher e família burguesa. In: DEL PRIORE, M (Org). História das mulheres no Brasil. 10 ed. São Paulo: Contexto, 2012.

FOUCAULT, M. As palavras e as coisas: uma arqueologia das ciências humanas. trad. Salma Tannus Muchail, São Paulo: Martins fontes, 2000.

. Verdade e subjectividade (Howison Lectures). Revista de Comunicação e linguagem. $\mathrm{n}^{\circ}$ 19. Lisboa: Edições Cosmos, 1993. p. 203 a 223.

O Sujeito e o Poder. In: DREYFUS, Hubert; RABINOW, Paul. Michel Foucault: uma trajetória filosófica para além do estruturalismo e da hermenêutica. Trad. Vera Porto Carrero. Rio de Janeiro: Forense Universitária, 1995. p. 231-249.

LAURETIS, T. A tecnologia do gênero. In: HOLLANDA, H. B. Tendências e impasses: o feminismo como crítica da cultura. Rio de Janeiro: Rocco, 1994.

ROCHA, R. Procurando Firme. Ed. Reform. São Paulo: Moderna, 2009.

SANTOS, A. R. Literatura Infantil: o procedimento arquegenealógico nas miragens femininas e feministas. 2018. Dissertação (Mestrado em Linguística) - Universidade Estadual de Maringá, Maringá.

ZILBERMAN, R. \& CADEMARTORI, L. M. Literatura infantil: autoritarismo e emancipação. 2 ed. São Paulo: Ática, 1984. (Ensaios, 82). 